УДК 577.2

DOI: $10.33184 / s p b g b-2021-09-21.21$

\title{
Роль генов регуляции синаптической пластичности в формировании особенностей пространственного мышления человека
}

( С Казанцева А.В. ${ }^{1,2^{*}}$, Еникеева Р.Ф. ${ }^{1,2}$, Давыдова Ю.Д. ${ }^{1}$, Мустафин Р.Н. ${ }^{3}$, Тахирова 3.Р. ${ }^{2}$, Лобаскова М.М. ${ }^{4}$, Гарданова Л.Т. ${ }^{5}$, Федореева К.С. ${ }^{5}$, Малых С.Б. ${ }^{4}$, Хуснутдинова Э. К. ${ }^{1,3}$

${ }^{1}$ Институт биохимии и генетики Уфримского федерального исследовательского центра Российской академии наук

450054 г. Уфра, проспект Октября, 71 лит. E.

${ }^{2}$ Российская академия образования, Центр междисциплинарных исследований в сорере наук об образовании

119121 г. Москва, ул. Погодинская, 8.

${ }^{3}$ Башкирский государственный медицинский университет

450008 г. Уфра, ул. Ленина, 3.

${ }^{4}$ Психологический институт Российской академии образования 125009 г. Москва, ул. Моховая, 9/4.

${ }^{5}$ Башкирский государственный университет 450076 г. Уфа, ул. Заки Валиди, 32.

\section{*Email:Kazantsa@mail.ru}

В результате оценки основного эффекта полиморфных вариантов генов регуляции синаптической пластичности (NGF, NRXN1, KIBRA, NRG1, BDNF, GRIN2B, APOE, SNAP25) и эфрфекта ген-средовых взаимодействий в формирование индивидуальных особенностей пространственного мышления была продемонстрирована ассоциация аллеля Т полиморфного локуса rs17070145 в гене KIBRA с более высоким уровнем пространственного мышления ( $\beta=1.32 ; \mathrm{P}=0.003$; $\left.\mathrm{P}_{\mathrm{FDR}}=0.037\right)$ по сравнению с носителями генотипа rs $17070145^{\star} \mathrm{CC}$ у индивидов без когнитивных нарушений при коррекции на наличие «рискового» аллеля $A P O E$ є4. Были выявлены модели ген-средовых взаимодействий, детерминирующие межиндивидуальную вариативность в пространственных способностях, включающие табакокурение и локус rs17070145 в гене KIBRA $(\beta=3.74 ; \mathrm{P}=0.010)$; место воспитания в детстве и варианты гена $A P O E(\beta=-6.94 ; \mathrm{P}=$ $0.0002)$.

Ключевые слова: KIBRA; аполипопротеин Е; когнитивные способности; мысленное вращение предметов; линейная регрессия; ген-средовые взаимодействия.

В настоящее время индивидуальная успешность в STEM-областях (от англ. Science, Technology, Engineering, Mathematics) в большей мере связана с уровнем развития особенностей пространственного мышления, позволяющих эффективно оперировать пространственными отношениями, ориентироваться в пространстве и воспринимать перспективу, а также с успешным обучением в школе по естественнонаучным дисциплинам. Таким образом, возникает необходимость разработки методов оценки про- 
странственных способностей, основанных на молекулярно-генетических, эпигенетических и социальных предикторах.

Согласно результатам близнецовых исследований, индивидуальные различия в особенностях пространственного мышления опосредованы комплексными механизмами, среди которых важная роль принадлежит взаимодействию генетического и средового компонента. В частности, особенности когнитивного фуннкционирования могут быть обусловлены особенностями функционирования генов, участвующих в регуляции нейрогенеза и синаптической пластичности, включая гены нейротрофических фракторов головного мозга (BDNF, NGF), нейрексина 1 (NRXN1), нейрегулина 1 (NRG1), синаптосомально-ассоциированного белка (SNAP25), глутаматергического рецептора (GRIN2B) (Казанцева и др., 2020; Mustafin et al., 2020). Помимо генно-кандидатного подхода, использованный Papassotiropoulos с коллегами (2006) полногеномный анализ ассоциаций (GWAS) позволил идентифицировать полиморфный локус rs 17070145, локализованный в интроне 9 гена KIBRA (KIdney and BRAin expressed protein) и ассоциированный с эпизодической памятью. Необходимо отметить, что ранее была показана необходимость включения индивидуального варианта в гене аполипопротеина $\mathrm{E}$ $(A P O E)$ (в частности, ع4-аллеля) в качестве ковариаты при оценке генетического эффректа на снижение когнитивного функционирования (Sasayama et al., 2020). Поскольку к настоящему времени число исследований, включающих анализ генов регуляции синаптической пластичности при изучении особенностей формирования пространственного мышления у здоровых людей без когнитивного дефицита, немногочисленно, мы предположили, что такие гены могут быть связаны не только с когнитивными нарушениями, но и с когнитивными способностями у здоровых индивидов.

Исходя из вышеизложенного, целью настоящего исследования являлась оценка основного эффекта полиморфных вариантов генов регуляции синаптической пластичности и гена $A P O E$, а также эфффекта ген-средовых взаимодействий в фрормирование особенностей пространственного мышления у индивидов без когнитивных нарушений.

В качестве материала в настоящем исследовании использовалась ДНК 1011 индивидов без когнитивных нарушений (80\% женщин) в возрасте 18-25 лет (средний возраст: $19.79 \pm 1.69$ лет) - студентов ВУЗов РФ разной этнической принадлежности (535 русских, 231 татар, 160 удмуртов, 85 индивидов смешанной этнической принадлежности). Включенные в исследование индивиды не состояли на учёте у психиатра и нарколога. Оценка пространственных способностей проводилась с помощью батареи тестовых заданий, оцениваемых как число правильных ответов при ответе на вопросы о вращении 3D фигур («shape rotation»), и реализованной в цифровом формате на психодиагностической платфрорме Российской академии образования. У всех индивидов была собрана информация социального характера, включающая этническую принадлежность до трёх поколений, особенности детско-родительских отношений (стиль родительского воспитания, эпизоды плохого обращения в детстве, воспитание в полной/неполной семье), уровень доходов семьи, возраст матери и отца при рождении ребёнка, вес ребёнка при рождении, место воспитания, число детей в семье и порядок рождения, знание своего родного языка (билингвизм), наличие хронических заболеваний и табакокурения. Все участники заполнили добровольное согласие на участие в исследовании. Исследование было одобрено биоэтическим комитетом ИБГ УФИЦ $\mathrm{PAH}$.

Для молекулярно-генетического анализа полиморфных локусов была использована ДНК, выделенная методом фенол-хлороформной экстракции. Генотипирование 10 полиморфрных локусов генов NGF (rs6330), NRXN1 (rs1045881, rs4971648), KIBRA (rs17070145), NRG1 (rs6994992), BDNF (rs6265), GRIN2B (rs3764030), APOE (rs7412, rs429358), SNAP25 (rs363050) проводилось методом ПЦР в реальном времени с использованием коммерческих наборов (LGC Genomics, UK) на амплификаторе «CFX96» 
(BioRad, США) с возможностью проведения анализа флуоресценции по конечной точке. Генотипы в гене $A P O E$ были сгруппированы на основании наличия аллелей $\varepsilon 2, \varepsilon 3$, $\varepsilon 4$.

Статистическая обработка результатов включала линейный регрессионный анализ с включением половой, этнической принадлежности и наличия «рискового» аллеля APOE \&4 в качестве ковариат с использованием аддитивной, доминантной и рецессивной статистических моделей (PLINK v.1.09). Оценка эфффекта ген-средовых взаимодействий была осуществлена с помощью множественного линейного регрессионного анализа, в котором в качестве независимых переменных выступали полиморфные локусы, социальные фракторы, половая и этническая принадлежность, в то время как уровень пространственного мышления - в качестве зависимой переменной. Стратификационный анализ был проведен с использованием непараметрического критерия МаннаУитни (SPSS 23). Процедура FDR (False Discovery Rate) была использована для коррекции на множественность сравнений (PLINK v.1.09).

В результате статистической обработки результатов, оценивавшей эфффект десяти изученных полиморфных локусов генов регуляции синаптической пластичности с включением половой, этнической принадлежности и наличия «рискового» аллеля APOE \&4 в качестве ковариат, в аддитивной модели была обнаружена ассоциация аллеля Т полиморфного локуса rs17070145 в гене KIBRA с более высоким уровнем пространственного мышления ( $\left.\beta=1.32 ; \mathrm{P}=0.003 ; \mathrm{P}_{\mathrm{FDR}}=0.037\right)$ по сравнению с носителями генотипа rs $17070145^{\star} \mathrm{CC}$.

Вторым этапом обработки результатов являлась оценка эффекта ген-средовых взаимодействий, учитывающего, наряду с генетическими вариантами, вовлеченность различных социальных параметров. Таким образом, было показано, что табакокурение модулирует ассоциацию локуса rs17070145 в гене KIBRA с индивидуальными различиями в пространственных способностях $(\beta=3.74 ; \mathrm{P}=0.010)$. В частности, более высокий уровень пространственного мышления статистически значимо более характерен для носителей минорного аллеля Т локуса rs17070145, заявивших о табакокурении, по сравнению с теми, кто отрицал у себя наличие такого поведения $\left(\beta=4.59 ; \mathrm{P}_{\mathrm{FDR}}=\right.$ 0.004). Кроме того, модель, включающая в себя варианты гена APOE и место воспитания в детстве, также достигла уровня статистической значимости $(\beta=-6.94 ; \mathrm{P}=$ 0.0002). Причем, наилучший уровень пространственных способностей был обнаружен у носителей «благоприятного» аллеля $A P O E \varepsilon 2$, воспитанных в сельской местности, по сравнению с теми, кто провел свое детство в городских условиях $(\beta=-6.04 ; \mathrm{r} 2=0.06$; $\left.\mathrm{P}_{\mathrm{FDR}}=0.021\right)$. Таким образом, на основании полученных нами данных, можно предположить неблагоприятный эфрфект воспитания в городской местности, который проявляется даже в случае наличия «благоприятного» аллелея $A P O E$ ع2, связанного с увеличением нейрональной активности (Davis et al., 2020).

Согласно ранее опубликованным данным, полиморфный локус rs17070145 в гене KIBRA является фрункционально-значимым, поскольку была показана связь мажорного аллеля C со снижением объема серого вещества в некоторых отделах головного мозга по сравнению с носителями генотипа rs17070145*TT как у лиц зрелого возраста (Li et al., 2020), так и у более молодых индивидов (Wang et al., 2013). Таким образом, идентифицированный в нашем исследовании эфффект минорного аллеля Т в гене KIBRA на улучшение пространственного мышления согласуется с вышеуказанными работами, демонстрирующими ухудшение когнитивного функционирования у носителей мажорного аллеля С в этом локусе. Нашей исследовательской группой также был выявлен эффект ген-средового взаимодействия, включающий вариант гена KIBRA и табакокурение. В опубликованных источниках также есть свидетельства о совместной вовлеченности никотина и гена KIBRA в формирование когнитивного функционирования. В частности, меньшее количество постоянных ошибок в когнитивных тестах наблюда- 
лось у лиц с никотиновой зависимостью по сравнению с теми, кто злоупотреблял табакокурением в прошлом, но только при наличии у них аллеля rs $17070145^{\star}$ Т в гене KIBRA (Zhang et al., 2009). Примечательно, что в нашем исследовании также была обнаружена ассоциация минорного аллеля Т с более высокими способностями к мысленному вращению предметов, которая наблюдалась у индивидов, заявивших о табакокурении, по сравнению с теми, кто отрицал у себя наличие такого поведения.

Полученные нами данные свидетельствуют об основном эфффекте генов KIBRA (на уровне полиморфных вариантов rs17070145) и APOE на формирование особенностей пространственного мышления у индивидов без когнитивных нарушений. Причем, наличие табакокурения и особенности места воспитания у респондентов оказывали позитивный модулирующий эффрект на улучшение изученных когнитивных способностей у носителей минорного аллеля Т в гене KIBRA и 22 в гене APOE, соответственно.

Работа выполнена в рамках государственного задания Минобрнауки РФ (№AAАAA21-121011990119-1). Образцы ДНК взяты из ЦКП "Коллекция биологических материалов человека" ИБГ УФИЦ РАН, поддержанного Программой биоресурсных коллекций ФАНО России (соглашение № 007-030164/2).

\section{Литература}

1. Казанцева А.В., Еникеева Р.Ф., Романова А.Р., и др. Взаимосвязь стрессобусловленного когнитивного функционирования с вариантами генов регуляции синаптической пластичности // Генетика. 2020. Т. 56. № 1. С. 98-106.

2. Mustafin R.N., Kazantseva A.V., Malykh S.B. Khusnutdinova E.K. Genetic mechanisms of cognitive development // Russian Journal of Genetics. 2020. V. 56(8). P. 891-902.

3. Sasayama D., Hattori K., Yokota Y. et al. Increased apolipoprotein E and decreased TNF- $\alpha$ in the cerebrospinal fluid of nondemented APOE- $\varepsilon 4$ carriers // Neuropsychopharmacol. Rep. 2020. V. 40(2). P. 201-205.

4. Papassotiropoulos A., Stephan D.A., Huentelman M.J. et al. Common Kibra alleles are associated with human memory performance // Science. 2006. V. 314. P. 475-478.

5. Li R., Wan W., Li J. KIBRA polymorphism modulates gray matter volume to influence cognitive ability in the elderly // Brain Imaging Behav. 2020. V. 14(5). P. 1388-1394.

6. Wang D., Liu B., Qin W., Wang J., Zhang Y., Jiang T., Yu C. KIBRA gene variants are associated with synchronization within the default-mode and executive control networks // Neuroimage. 2013. V. 69. P. 213-222.

7. Zhang H., Kranzler H.R., Poling J., Gruen J.R., Gelernter J. Cognitive flexibility is associated with KIBRA variant and modulated by recent tobacco use // Neuropsychopharmacology. 2009. V. 34(12). P. 2508-2516. 
The role of synaptic plasticity genes in individual variance in spatial ability in humans

A.V. Kazantseva ${ }^{1,2^{*}}$, R.F. Enikeeva ${ }^{1,2}$, Yu. D. Davydova ${ }^{1}$, R.N. Mustafin ${ }^{3}$, Z.R. Takhirova ${ }^{2}$, M.M. Lobaskova ${ }^{4}$, L.T. Gardanova ${ }^{5}$, K.S. Fedoreeva ${ }^{5}$, S.B. Malykh" ${ }^{4}$, E.K. Khusnutdinova ${ }^{1,3}$

${ }^{1}$ Institute of Biochemistry and Genetics - Subdivision of the Ufa Federal Research Centre of the Russian Academy of Sciences

71 Prospekt Oktyabrya, 450054 Ufa, Republic of Bashkortostan, Russia.

${ }^{2}$ Russian Academy of Education, Centre of interdisciplinary research in education 8 Pogodinskaya Street, 119121 Moscow, Russia.

${ }^{3}$ Bashkir State Medical University

3 Lenin Street, 450008 Ufa, Republic of Bashkortostan, Russia.

${ }^{4}$ Psychological Institute of Russian Academy of Education

9/4 Mokhovaya Street, 125009 Moscow, Russia.

${ }^{5}$ Bashkir State University

32 Zaki Validi Street, 450076 Ufa, Russia.

*Email: Kazantsa@mail.ru

Conducted statistical analysis aimed to examine the main effect of synaptic plasticity gene polymorphisms including the NGF, NRXN1, KIBRA, NRG1, BDNF, GRIN2B, APOE, and SNAP25 genes, and gene-environment interactions effect in individual differences in spatial abilities made it possible to identify the association of the KIBRA rs $17070145 \mathrm{~T}$-allele and higher mental rotation $\left(\beta=1.32 ; \mathrm{P}=0.003 ; \mathrm{P}_{\mathrm{FDR}}=0.037\right)$ compared to rs17070145 CCgenotype carriers without cognitive impairments while controlling for the "risky" APOE $\varepsilon 4$ allele. The gene-environment interaction models, which determined individual variance in spatial ability, were observed. They included present smoking and KIBRA rs17070145 ( $\beta=$ 3.74; $P=0.010)$; as well as place of residence in childhood and $A P O E$ variants $(\beta=-6.94 ; P$ $=0.0002)$.

Keywords: KIBRA, apolipoprotein E, cognitive abilities, mental rotation, linear regression, gene-environment interactions. 